\title{
Sistem Pengendalian Persediaan Barang Berbasis Website dengan Metode Economic Order Quantity dan Reorder Point
}

\author{
Seppy Ayu Rachmawati ${ }^{\mathrm{a} 1}$, Lutfi Syafirullah ${ }^{\mathrm{a} 2}$, Muhammad Nur Faiz Penulis ${ }^{\mathrm{a} 3}$

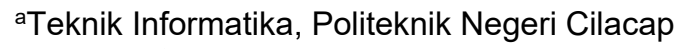 \\ Jalan Dokter Soetomo No.1 Jawa Tengah, Indonesia \\ 1seppyayur29@gmail.com \\ 2syafirullah.lutfi@pnc.ac.id \\ 3faiz@pnc.ac.id
}

\begin{abstract}
Inventory of goods is one of the important factors in developing a business. This inventory affects operational costs. Excess inventory will also lead to greater storage and maintenance costs. Meanwhile, a lack of inventory will cause stock out. Website Inventory information system with the Economic Order Quantity (EOQ) and ReOrder Point (ROP) method can be an alternative to overcome this problem. This information system was developed using the SDLC (System Development Life Cycle) development method. The programming language used is PHP Hypertext Preprocessor, MySQL as database, and Xampp as a web server. EOQ method can determine the level of inventory required by the company. Meanwhile, the ROP to determine the time an item is in the warehouse must be added to the inventory before it runs out. This research results that the determination of the quantity of purchase inventory using the EOQ method and the ROP method is more efficient and the inventory becomes more optimal so that the store can get maximum profit. The results of the system functionality test show that this system works very well.
\end{abstract}

Keywords: : Inventory, Goods, EOQ, ROP, Website

\section{Pendahuluan}

Perkembangan Teknologi informasi membuat persaingan global semakin ketat sehingga terus memunculkan inovasi terbaru termasuk dalam dunia industri [1]. Perkembangan ini juga berkaitan pada kebanyakan pelaku bisnis seperti toko menyelesaikan pekerjaan secara manual. Keberhasilan pelaku bisnis untuk mempertahankan bisnisnya tidak terlepas dari pengelolaan persediaan barang yang dapat memenuhi kebutuhan konsumen [2]. Pengendalian jumlah persediaan salah satu faktor terpenting dalam mengoptimalkan persediaan. Pengendalian persediaan merupakan kegiatan dalam mengelola persediaan agar sesuai kebutuhan dan tetap stabil [3].

Toko Wiwik merupakan salah satu toko yang bergerak dalam bidang kosmetik yang menyediakan segala macam jenis kosmetik. Berdasarkan hasil wawancara dengan pihak toko, didapatkan informasi bahwa toko ini berdiri sejak tahun 2000. Data penjualan dan pelanggan yang relatif meningkat setiap tahunnya seperti yang ditunjukan dengan gambar 1 dari tahun 20152019. 


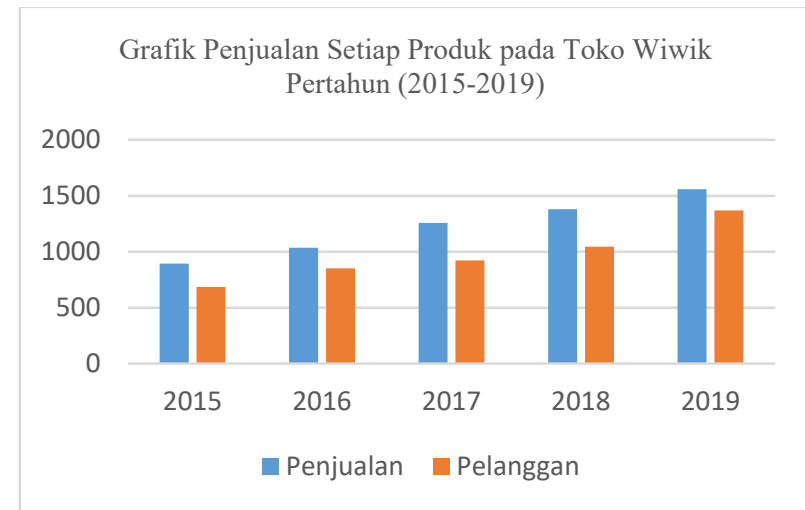

Gambar 1. Grafik Data Penjualan

Pada Gambar 1 dapat dilihat data penjualan dan data pelanggan yang terus meningkat. Tahun 2015 sampai tahun 2019. Pada tahun 2015 Toko Wiwik telah melakukan penjualan sebanyak 894 untuk setiap produknya dan 686 pelanggan dalam setahun, pada tahun 2016 sebanyak 1035 untuk setiap produknya dan 852 pelanggan, pada tahun 2017 sebanyak 1256 untuk setiap produknya dan 921 pelanggan, pada tahun 2018 sebanyak 1380 untuk setiap produknya dan 1045 pelanggan, dan pada tahun 2019 sebanyak 1560 untuk setiap produknya dan 1369 pelanggan.

Berdasarkan observasi yang dilakukan pada toko Wiwik, Permasalahan yang terjadi adalah saat ini adalah ketika adanya pengeluaran biaya yang sangat besar dalam pembelian barang oleh karyawan toko dari suplier yang tidak terkendali dan barang mengalami penumpukan serta terdapat barang yang mendekati tanggal kadaluarsa belum terjual namun karyawan toko sudah menambah persediaan barang. Info persediaan barang didapatkan dengan cara melihat data persediaan barang yang ditulis secara manual oleh karyawan toko dimana karyawan toko harus mencari data tersebut terlebih dulu dan biasanya data yang didapat sering tidak akurat. Permasalahan lain yang timbul adalah saat melakukan persediaan barang yang sedikit dalam hal untuk menghemat biaya. Hal ini dapat mengakibatkan kehabisan stok pada saat permintaan barang itu melonjak sehingga membuat pelanggan merasa tidak puas dan hal ini menyebabkan penghasilan toko berkurang maka toko harus memperhitungkan pengendalian persediaan barang yang lebih optimal. Oleh karena itu untuk mengurangi jumlah pengeluaran biaya yang sangat besar dan jumlah barang yang efisien untuk dibeli diperlukan suatu metode EOQ (Economic Order Quantity) untuk menentukan minimum jumlah unit dan metode ROP (Reorder Point) untuk menentukan waktu terbaik dalam melakukan pemesanan.

Beberapa penelitian sebelumnya yang dilakukan terkait sistem pengendalian persediaan barang antara lain tahun 2016 diteliti oleh Wanda mengenai Sistem Informasi Manajemen Persediaan Menggunakan Metode Economic Order Quantity (EOQ) Studi Kasus ARC Komputer. Penelitian ini menghasilkan sistem penjualan untuk transaksi penjualan dan pembelian, menentukan jumlah kuantitas setiap kali pesan dan memonitor pada saat dilakukan pemesanan kembali, dan pencatatan persediaan [4].

Penelitian selanjutnya dengan judul Sistem Pengendalian Persediaan Stok Barang Menggunakan Metode Double Exponential Smoothing dan Economy Order Quantity (EOQ) Studi Kasus UD Jasmine dilakukan oleh Deasy Wulansari pada tahun 2016. Hasil dari penelitian ini yaitu sistem dapat menentukan jumlah barang yang harus dipesan untuk setiap pemesanannya, jumlah persediaan pengaman (safety stock), dan jumlah stok barang minimal untuk melakukan pemesanan Kembali [5]. Penelitian serupa mengenai Sistem Informasi Persediaan barang dilakukan oleh Rasyid lqbal tahun 2016, hasilnya sistem ini dapat menghitung persediaan dengan menggunakan metode rata-rata dan Sistem dapat menampilkan pencatatan persediaan [6]. Perbedaan dengan penelitian ini yaitu penelitian ini berfokus pada pengembangan sistem untuk pengelolaan persediaan barang dengan metode EOQ dan ROP agar dapat membantu toko Wiwik ini dalam mengelola atau pengendalian persediaan barang terutama saat proses pembelian barang.

Pengendalian adalah suatu usaha yang sistematis untuk menentukan standar yang sesuai agar sumber daya digunakan secara efektif dan efisien [1],[7]. Pengendalian merupakan proses 
memantau dan mengatur suatu organisasi dan segenap anggotanya dalam menjalankan kegiatan untuk mencapai tujuan secara efektif dan efisien [8] Persediaan yaitu suatu istilah untuk menunjukkan suatu sumber daya pada organisasi yang disimpan untuk pemenuhan permintaan [9].

Web browser merupakan perangkat lunak yang digunakan untuk mencari informasi, transaksi email, berkomunikasi, berbelanja secara digital [10]. Situs pada internet yang mampu menyediakan informasi dalam bentuk teks, gambar, suara, maupun gambar bergerak (Animasi) [11]. Situs web harus memenuhi prinsip dasar seperti mudah diakses dan mudah digunakan [12].

\section{Metode}

EOQ merupakan jumlah unit (kuantitas) barang yang dapat dibeli dengan biaya minimal. Tujuan metode persediaan ini adalah menentukan jumlah pesanan yang dapat meminimumkan biaya penyimpanan dan biaya pemesanan persediaan [13]. EOQ adalah besarnya pesanan jumlah ordering costs dan carrying costs per-tahun yang minimal. Rumus untuk menghitung $E O Q$ [14]:

$$
E O Q=\sqrt{\frac{(2 \times D \times S)}{C}}
$$

$$
\begin{aligned}
& \text { Keterangan : } \\
& D=\text { Jumlah permintaan selama } 1 \text { periode } \\
& S=\text { Biaya setiap melakukan pesanan } \\
& C=\text { Biaya penyimpanan. }
\end{aligned}
$$

ROP dapat dilakukan dengan menentukan jumlah barang selama lead time ditambah dengan satu persentase tertentu dan menentukan jumlah pemakaian barang selama lead time ditambah dengan persediaan pengamanan yang ditetapkan [14]. Rumus untuk menghitung ROP :

$$
R O P=D \times T+S S
$$

$$
\begin{aligned}
& \text { Keterangan : } \\
& D=\text { Tingkat pemakaian rata-rata perhari } \\
& T=\text { Lead time } \\
& \text { SS = Safety stock }
\end{aligned}
$$

\section{Hasil dan Pembahasan}

\subsection{Perancangan Sistem}

Rancangan sistem informasi yang dikembangkan menggunakan Sequence Diagram dan Entity Relationship Diagram (ERD) dapat dilihat pada gambar 3, 4 dan 5.

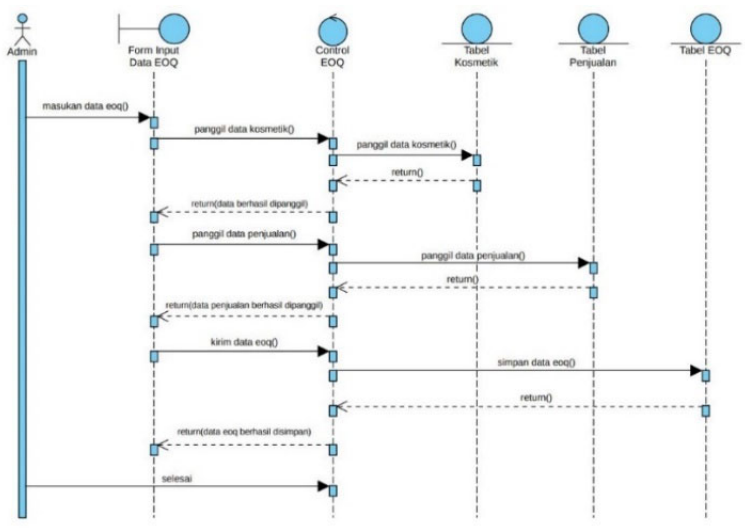

Gambar 2. Sequence diagram Menganalisa EOQ. 
Pada Gambar 2 menjelaskan proses dimana admin melakukan proses analisa atau menginput data untuk menghitung eoq. Setelah selesai menginput data maka form atau antarmuka akan mengirim data ke Control EOQ dan data perhitungan akan disimpan pada tabel $E O Q$.

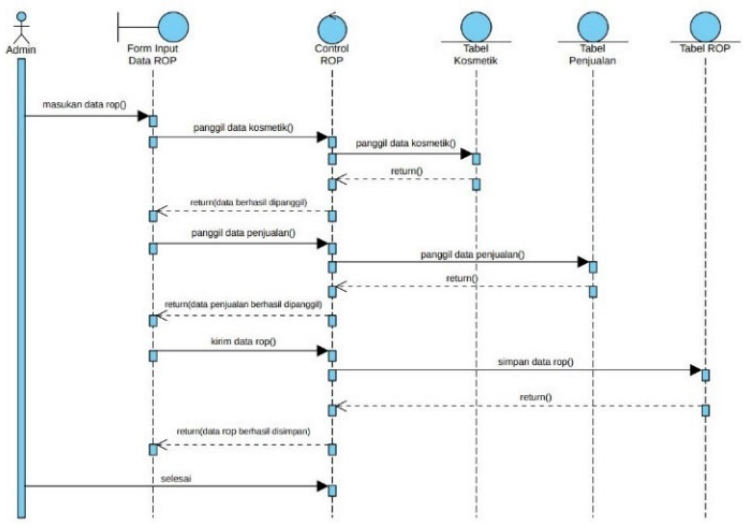

Gambar 3. Sequence diagram Menganalisa ROP

Pada Gambar 3 menjelaskan proses dimana admin melakukan proses analisa atau menginput data untuk menghitung rop. Setelah selesai menginput data maka form atau antarmuka akan mengirim data ke Control ROP dan data perhitungan akan disimpan pada tabel ROP.



Gambar 4. ERD Sistem Pengendalian Persediaan Barang

Pada gambar 3 menjelaskan tentang entitas admin memiliki hubungan many to many dengan entitas kosmetik yaitu satu atau banyak admin dapat melakukan penjualan atau pembelian satu barang atau banyak barang diwaktu yang sama., entitas kosmetik memiliki hubungan one to one dengan entitas suplier yaitu satu barang hanya memiliki satu suplier.

\subsection{Pembahasan EOQ dan ROP}

\subsubsection{Kebutuhan Bahan baku}

Perhitungan EOQ membutuhkan Bahan baku. Berdasarkan sampel yang ada sebagai studi kasus diketahui tabel data kebutuhan bahan baku selama 1 periode, seperti pada tabel berikut ini : 
Tabel 1. Data kebutuhan bahan baku selama 1 periode

\begin{tabular}{ccccccc}
\hline No & $\begin{array}{c}\text { Nama Bahan } \\
\text { Baku }\end{array}$ & Qty(pcs) & $\begin{array}{c}\text { Harga (per Pcs } \\
\text { \& IDR) }\end{array}$ & $\begin{array}{c}\text { Harga Total } \\
\text { (IDR) }\end{array}$ & $\begin{array}{c}\text { Biaya } \\
\text { Pemesanan (IDR) }\end{array}$ & $\begin{array}{c}\text { Harga Penyimpanan } \\
\text { (IDR) }\end{array}$ \\
\hline 1 & X & 135 & 19.800 & 2.268 .000 & 9.000 & 4.500 \\
2 & Y & 150 & 29.500 & 4.260 .000 & 7.000 & 4.300 \\
3 & Z & 150 & 27.000 & 3.525 .000 & 9.000 & 4.500 \\
\hline
\end{tabular}

Tabel 2. Data pemakaian barang di hari yang sama

\begin{tabular}{cccc}
\hline No & Nama Bahan Baku & Jumlah & Harga Total (IDR) \\
\hline 1 & $\mathrm{X}$ & 21 & 415.800 \\
2 & $\mathrm{Z}$ & 11 & 297.000 \\
3 & $\mathrm{Z}$ & 22 & 594.000 \\
4 & $\mathrm{Y}$ & 10 & 295.000 \\
5 & $\mathrm{X}$ & 27 & 796.500 \\
6 & $\mathrm{X}$ & 28 & 554.400 \\
7 & $\mathrm{Z}$ & 54 & 1.458 .000 \\
8 & $\mathrm{Z}$ & 14 & 378.000 \\
9 & $\mathrm{Y}$ & 15 & 442.500 \\
10 & $\mathrm{Z}$ & 15 & 405.000 \\
11 & $\mathrm{X}$ & 32 & 633.600 \\
12 & $\mathrm{Y}$ & 13 & 383500 \\
13 & $\mathrm{Y}$ & 16 & 472.000 \\
\hline
\end{tabular}

\subsubsection{Perhitungan EOQ}

1. Menghitung EOQ Barang $X$

$E O Q=\sqrt{\frac{(2 \times D \times S)}{C}}=\sqrt{\frac{(2 \times \text { jumlah permintaan } \times \text { biaya pemesanan })}{\text { biaya penyimpanan }}}=\sqrt{\frac{(2 \times 81 \times 9000)}{4500}}=\sqrt{\frac{1458000}{4500}}$ $=\sqrt{324}=18$

Jadi, EOQ Barang X adalah 18 pcs

2. Menghitung EOQ Barang $Y$

Jadi, EOQ Barang $Y$ adalah 16 pcs

3. Menghitung EOQ Barang $Z$

Jadi, EOQ Barang Z adalah 22 pcs

\subsubsection{Perhitungan ROP}

Analisis ROP dapat diketahui jika lead time dan penggunaan selama periode (safety stok). Jika toko memiliki waktu tunggu (lead time) 3 hari dengan safety stok tergantung dari banyaknya data pemakaian per hari untuk tiap barang, maka :

1. Menghitung ROP Barang $X$

Rata-rata pemakaian = total barang di hari itu $/$ banyak data pemakaian $=81 / 3=27$ Safety stok $=($ pemakaian maks - pemakaian $\min ) \times$ lead time $=(32-21) \times 3=15$ $\mathrm{ROP}=\mathrm{D} \times \mathrm{T}+\mathrm{SS}=$ rata-rata pemakaian $\times$ lead time $\times$ safety stok $=27 \times 3+15=96$ Jadi, ROP Barang $X$ adalah 96

2. Menghitung ROP Barang $Y$ Jadi, ROP Barang $Y$ adalah 81

3. Menghitung ROP Barang Z Jadi, ROP Barang $Z$ adalah 162

Berdasarkan perhitungan tersebut maka jumlah perhitungan persediaan pada toko tersebut dapat dijadikan acuan untuk perhitungan ROP (Reorder Point), dimana harus menentukan safety stok terlebih dahulu. 
Tabel 3. Bahan Baku X

\begin{tabular}{lccl}
\hline \multicolumn{1}{c}{ Ket } & Kebijakan Toko & Metode EOQ & Kesimpulan \\
\hline Rata-rata beli bahan baku & - & 27 & Barang X harus melakukan \\
Total cost & 70.000 & 13.500 & persediaan barang sebanyak \\
Frekuensi pemesanan & 50 & 18 & 18 pcs ketika stok minimum 96 \\
Reorder point & - & 96 & pcs \\
\hline
\end{tabular}

Bahan baku $Y=81$ Pcs dan bahan baku Z= 162 Pcs

\subsection{Implementasi Sistem}

Implementasi dari Sistem Pengendalian Persediaan Barang menampilkan hasil capture/screenshoot program aplikasi. Hasil tampilan sistem ini dapat dilihat pada gambar 6,7 dan 8.

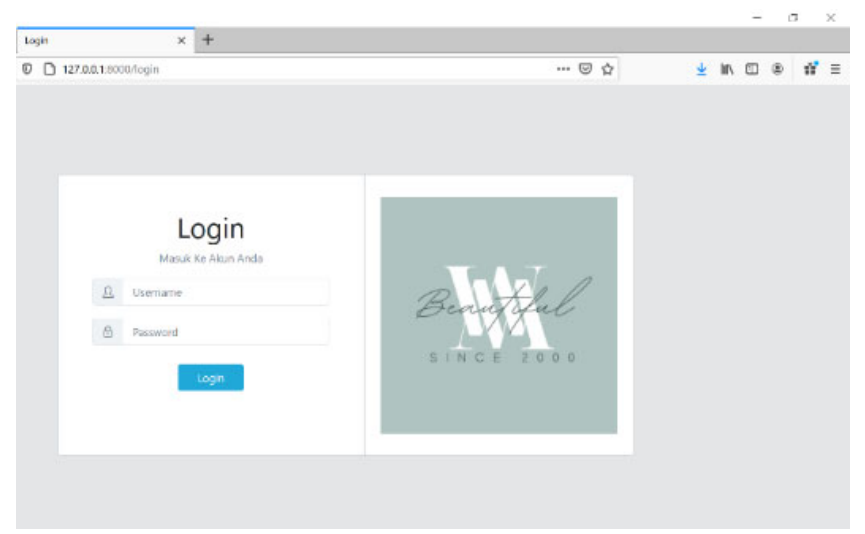

Gambar 5. Halaman Login Sistem

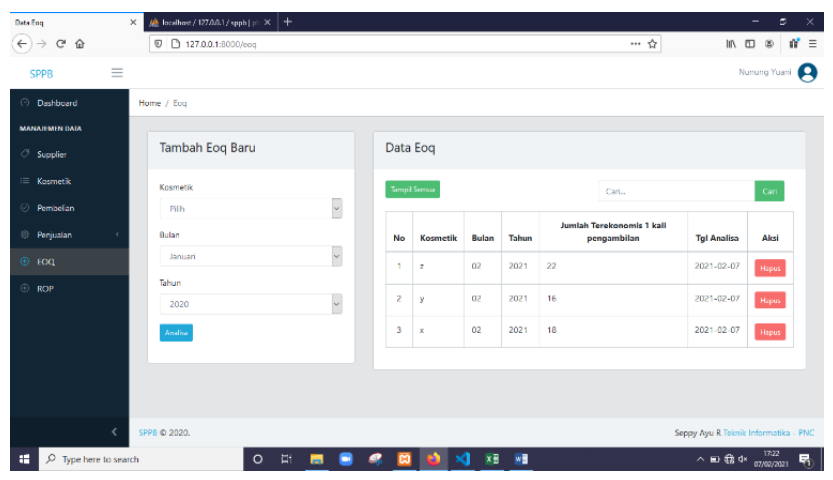

Gambar 6. Analisa Perhitungan EOQ 


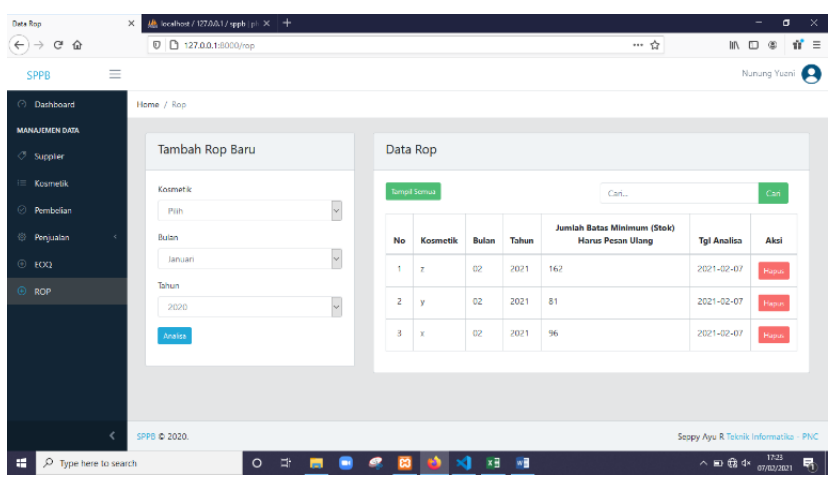

Gambar 7. Analisa Perhitungan ROP

Pada Gambar 5, Tampilan form Login berfungsi untuk masuk ke dalam sistem dengan cara memasukkan username dan password yang valid. Pada Gambar 6 dan 7, terdapat button analisa untuk melakukan perhitungan dan button tampil untuk menampilkan data perhitungan.

\subsection{Pengujian Sistem}

Dalam pengujian ini, dilakukan dengan pengimplementasian Sistem Pengendalian Persediaan Barang pada toko Wiwik. Pada proses pengujian ini menggunakan skala likert untuk mengetahui tingkat keberhasilan secara fungsional.

Tabel 4. Hasil Kuisioner Pengujian Responden

\begin{tabular}{lllllll}
\hline \multicolumn{1}{c}{ Indikator } & \multicolumn{3}{c}{ Penilaian } & \multicolumn{2}{c}{ Bobo } \\
& $\mathbf{S}$ & $\mathbf{K}$ & $\mathbf{C}$ & $\mathbf{B}$ & $\mathbf{C}$ & $\begin{array}{c}\text { Cob } \\
\text { t }\end{array}$ \\
Sistem memudahkan dalam pengelolaan data penjualan dan pembelian & K & & & & B & \\
Sistem membantu dalam menyediakan informasi mengenai persediaan barang & 0 & 0 & 2 & 4 & 4 & 84 \\
Sistem memudahkan dalam menyampaikan informasi persediaan barang kepada & 0 & 0 & 0 & 7 & 3 & 80 \\
pemilik toko & 0 & 0 & 2 & 2 & 6 & 88 \\
Sistem memudahkan dalam hal pengendalian persediaan barang & 0 & 0 & 1 & 4 & 5 & 88 \\
Total & & & & & & 340 \\
Rata-rata & & & & & 85 \\
\hline
\end{tabular}

Tabel 5. Tabel Interval

\begin{tabular}{lll}
\hline No & \multicolumn{1}{c}{ Indeks } & \multicolumn{1}{c}{ Keterangan } \\
\hline 1 & $0-19,99 \%$ & Sangat Kurang (SK) \\
2 & $20-39,99 \%$ & Kurang (K) \\
3 & $40-59,99 \%$ & Cukup (C) \\
4 & $60-79,99 \%$ & Baik (B) \\
5 & $80-100 \%$ & Sangat Baik (SB) \\
\hline
\end{tabular}

Hasil kuisioner keseluruhan dapat disimpulkan bahwa sistem dinilai cukup baik dalam mengatasi permasalahan di Toko Wiwik. Berdasarkan hasil keseluruhan kuisioner bahwa $45 \%$ menyatakan Sangat Baik, 42,5\% menyatakan baik, dan 12,5\% menyatakan cukup terhadap sistem ini. Hasil keseluruhan dengan perhitungan skala likert sebesar 85 masuk dalam kualifikasi Sangat Baik yang berarti berhasil. Grafik hasil kuisioner secara keseluruhan dapat dilihat pada Gambar 4.23 


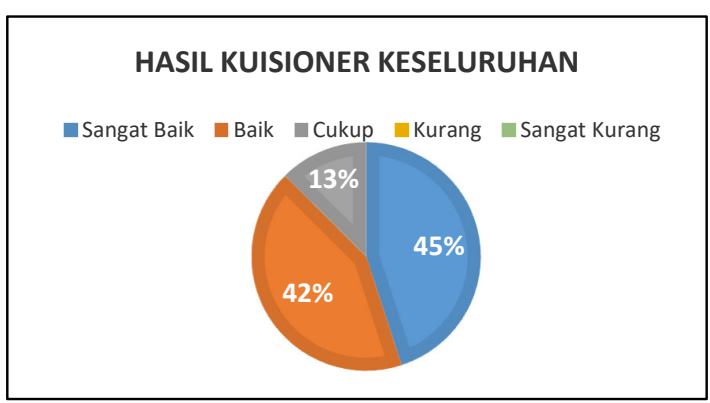

Gambar 8. Hasil Kuisioner Keseluruhan

\section{Kesimpulan}

Penelitian ini menghasilkan sebuah Sistem Pengendalian Persediaan Barang sebagai produk terapan yang sangat bermanfaat pada toko Wiwik dan sistem ini juga memiliki perhitungan EOQ dan ROP secara akurat, untuk menghitung jumlah persediaan dan memberikan perhitungan yang akurat di gudang. sehingga menean biaya operasional barang di Gudang.

\section{Daftar Pustaka}

[1] D. Guntara, M. Irwan, P. Nasution, and A. B. Nasution, "Implementasi Metode Economic Order Quantty Pada Aplikasi Pengendalian Bahan Produksi Sandal Mirado," J. Tek. Inform., vol. 13, no. 1, pp. 31-42, 2020.

[2] S. Fauziah and Ratnawati, "Penerapan Metode FIFO Pada Sistem Informasi Persediaan Barang," J. Tek. Komput., vol. 4, no. 1, pp. 98-108, 2018.

[3] N. Apriyani and A. Muhsin, "Analisis Pengendalian Persediaan Bahan Baku Dengan Metode Economic Order Quantity Dan Kanban Pada Pt Adyawinsa Stamping Industries," J. OPSI, vol. 10, no. 2, pp. 128-142, 2017.

[4] W. S. Pratama, "Sistem Informasi Manajemen Persediaan Menggunakan Metode Economic Order Quantity Studi Kasus di ARC Komputer," STMIK AKAKOM Yogyakarta, 2016.

[5] D. Wulansari, "Sistem Pengendalian Persediaan Stok Barang Menggunakan Metode Double Exponential Smoothing Dan Economy Order Quantity (EOQ) (Studi Kasus Ud Jasmine)," Universitas Jember, 2016.

[6] R. Iqbal, "Sistem Informasi Persediaan Barang Mengunakan Metode Rata-Rata ( Studi Kasus Prodist Souvenir )," STMIK AKAKOM Yogyakarta, 2016.

[7] A. Ridwan and R. Ajiono, "Pengendalian Biaya Dan Jadual Terpadu Pada Proyek Konstruksi," UkaRsT, vol. 1, no. 1, pp. 74-83, 2017.

[8] B. Kho, "Pengertian Pengendalian (Controlling) dan Empat Langkah Pengendalian," IImu Manajemen Industri, 2018.

[9] Suryadi, "Analisis Persediaan Bahan Baku pada Home Industry Tahu di Desa Raman Aji Kecamatan Raman Utara," J. Din., vol. 3, no. 2, pp. 53-65, 2017.

[10] M. F. Sidiq and M. N. Faiz, "Review Tools Web Browser Forensics untuk Mendukung Pencarian Bukti Digital," J. Edukasi dan Penelit. Inform., vol. 5, no. 1, p. 67, Apr. 2019.

[11] Q. Aini, I. M. Shofi, and E. F. M. Agustin, "Analisis Website Perpustakaan Universitas Islam Negeri Menggunakan Metode Benchmarking Dan Goal Oriented Requirments Engineering (Gore) Model (Studi Kasus: Uin Jakarta, Uin Yogyakarta Dan Uin Malang)," J. Tek. Inform., vol. 12, no. 2, pp. 159-166, 2019.

[12] Y. Ichsani, "Evaluasi Performa Usability Situs-Situs Web Perguruan Tinggi Negeri Di Indonesia Yang Terakreditasi 'a' Tahun 2013 Serta Perbandingan Kondisi Situs Web Tahun 2014 Dan 2017," J. Tek. Inform., vol. 10, no. 2, pp. 93-108, 2018.

[13] Nirwana, Sahrun, and N. E. Purwati, "Penerapan Metode Economic Order Quantity 
(Eoq) dalam Pengendalian Persediaan Bahan Baku (Gabah) pada Usaha Penggilingan Padi Sri Rezky Rahayu di Desa Padang Mekar Kecamatan Padangguni Kabupaten Konawe," Bus. UHO J. Adm. Bisnis, vol. 4, no. 1, pp. 1-10, 2019.

[14] T. Rafliana and B. R. Suteja, "Penerapan Metode EOQ dan ROP untuk Pengembangan Sistem Informasi Inventory Bengkel MJM berbasis Web," J. Tek. Inform. dan Sist. Inf., vol. 4, no. 2, pp. 345-354, 2018.

[15] W. Suryn, Software Quality Engineering: A Practitioner's Approach. New Jersey: Wiley Publishing, Inc., 2014.

[16] R. S. Pressman, Software Quality Engineering: A Practitioner's Approach. New Jersey, 2010.

[17] S. A. Rachmawati, L. Syafirullah, and M. N. Faiz, "Perancangan Sistem Pengendalian Persediaan Barang Menggunakan Metode EOQ dan ROP Berbasis Web," in Seminar Nasional Terapan Riset Inovatif (SENTRINOV) Ke-6, 2020, vol. 6, no. 1, pp. 778-786. 